\title{
Innovative Method for Ship Navigation Safety Risk Response in Landslide-Induced Wave
}

\author{
Peiyin Yuan (D), ${ }^{1}$ Pingyi Wang, ${ }^{2}$ and Yu Zhao ${ }^{2,3}$ \\ ${ }^{1}$ College of Shipping and Naval Architecture, Chongqing Jiaotong University, Chongqing 400074, China \\ ${ }^{2}$ College of River and Ocean Engineering, Chongqing Jiaotong University, Chongqing 400074, China \\ ${ }^{3}$ College of Architecture and Urban Planning, Chongqing Jiaotong University, Chongqing 400074, China
}

Correspondence should be addressed to Peiyin Yuan; yuan_pei_yin@163.com

Received 29 December 2020; Revised 6 March 2021; Accepted 18 May 2021; Published 28 May 2021

Academic Editor: Filipe Santos

Copyright ( $\odot 2021$ Peiyin Yuan et al. This is an open access article distributed under the Creative Commons Attribution License, which permits unrestricted use, distribution, and reproduction in any medium, provided the original work is properly cited.

When the bank of a reservoir slope slides along a weak structural plane at a high speed, "landslide slamming" will occur in the nearby water. The formation of landslide-induced waves is a serious threat to the safety of wharfs, shore marks, buildings in the water, and vessels navigating in reservoir areas. To ensure the safety of navigating ships, this study proposes a landslide-induced wave water ship navigation safety risk response technology. The propagation characteristics of landslide-induced waves are analysed based on a physical model experiment, and the characteristics of a ship's motion response and mooring cable tensions are studied under conditions of bow and stern mooring and multipoint mooring. The influences of the landslide-induced wave direction and ship navigation position on the ship rolling motion characteristics are discussed. The results of this study can further improve the navigation safety of ships in landslide-induced wave waters.

\section{Introduction}

When the bank of a reservoir slope along a weak structural plane slides at a high speed, the energy exchange between the landslide and water will lead to landslide-induced waves. Owing to the short time and massive impact of landslideinduced waves, they pose serious threats to the safety of wharfs, shore marks, buildings in the water, and navigation vessels in reservoir areas. To ensure the safety of ships during navigation and according to the Warning and Forecast Manual of Landslide Disaster in the Three Gorges Reservoir Area [1], it is very important to research and develop a ship navigation safety technique to cope with landslide-induced waves.

Scholars have studied model tests on landslide-induced waves, ship navigation safety, and risk response technologies to a certain extent. In the process of model testing, the mechanical, Froude, and Reynolds similarities are generally studied to improve the accuracy of the model tests and to avoid the scale effects of typical hydraulic flow phenomena $[2,3]$. Other studies have delved into the effects of test variables on landslide-induced waves, such as the still water depth, slide impact velocity, slide thickness, bulk slide volume, bulk slide density, slide impact angle, and grain diameter [4]. The same experts studied the characteristics of landslide-induced waves using physical model tests. Huang et al. [5] derived the amplitudes, wavelengths, and jet-flow heights of the initial stages of landslide-induced waves in shallow water. Some experts have used numerical simulations to study the characteristics of landslide-induced waves. Heller and Hager [6] observed the features of four wave types and directly predicted the wave type as a function of the slide parameters, slide impact angle, and still water depth. Ersoy et al. [7] established a propagation model and evaluated the characteristics of impulse waves. Ruffini et al. [8] focused on numerical aspects of far-field landslide and tsunami propagation to quantify the effects of the water body geometry. Fuchs et al. [9] designed a rectangular wave channel for studying wave runover.

In another study, Miller et al. [10] performed a model test on a $6.7 \mathrm{~m}$ long, $30^{\circ}$ slope, in which gravity accelerated the landslides into a $2.1 \mathrm{~m}$-wide and $33 \mathrm{~m}$-long wave flume. 
Heller and Hager [4] investigated impulse product parameters, including those concerning the still water depth, slide impact velocity, slide thickness, and bulk slide volume. Huang et al. [11] presented experimental models for two common failure types for high and steep slopes in the Three Gorges Reservoir.

Some experts have conducted 3D experiments. Kim et al. [12] presented subaerial landslides for generating highly nonlinear waves with complex wave patterns and runups. McFall et al. $[13,14]$ modelled a landslide-generated tsunami source and propagation scenarios in a three-dimensional tsunami wave basin and studied the tsunamis generated by three-dimensional deformable granular landslides on planar and conical hill slopes. Mohammed and Fritz [15] researched deformable granular landslides in three dimensions. Heller et al. [16] constructed a small-scale physical model for investigating the effects of the geometry on the landslidegenerated tsunami height, amplitude, period, and so on.

This paper proposes a response procedure to cope with the risk of ship navigation safety when subjected to landslide-induced waves. In addition, a physical model experiment to test such a procedure was conducted. The propagation characteristics of landslide-induced waves and the characteristics of a ship's motion response are studied under conditions of bow and stern mooring and multipoint mooring. The models provide a reference for the modelling of other types of landslide-induced waves.

\section{Testing Arrangement}

2.1. River. In this study, the river model was based on survey data of the field river topography in the Wanzhou stretch of Chongqing in the Three Gorges Reservoir Area. According to principles of geometric similarity, dynamic similarity, kinematic similarity, and connection with the test conditions, a physical model of the river course was constructed, with a geometric scale of $1: 70$. The central line of the river course was $48 \mathrm{~m}$, the upstream river course was $28 \mathrm{~m}$, and the downstream river course was $13 \mathrm{~m}$. There was a $90^{\circ}$ bend area in the central river course, in which the centre line length was $7 \mathrm{~m}$. The section for the river course model was trapezoidal, $8 \mathrm{~m}$ in width at the top, and $2.94 \mathrm{~m}$ in width at the bottom and had a $1.6 \mathrm{~m}$ maximum depth. The slopes on the left and right sides of the flume were $33^{\circ}$ and $20^{\circ}$, respectively. The river course is shown in Figure 1.

2.2. Chute. The landslide-induced wave generator mainly comprised chutes, slide frames, gates, and bottom trays. The chute was $2 \mathrm{~m}$ long and $1.6 \mathrm{~m}$ wide and had a maximum capacity of $1.95 \mathrm{~m}^{3}$. The chute was installed on the slide frame using a flexible chain, and the range of the chute dip angle was $30^{\circ}-80^{\circ}$. During the trial, when opening the gate, the gravity-driven motion of the granular material on the chute created a landslide that exchanged energy with the water body. To ensure the same friction coefficient for every landslide, the bottom of the chute was polished before each slide. After each case, the landslide was dried to prepare for the next test. The chute is shown in Figure 2.

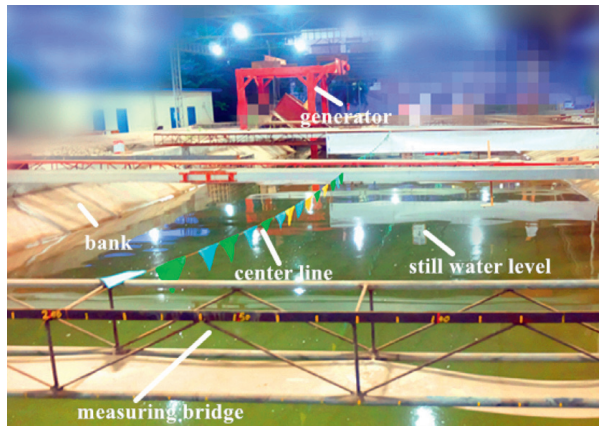

FIgURE 1: River.

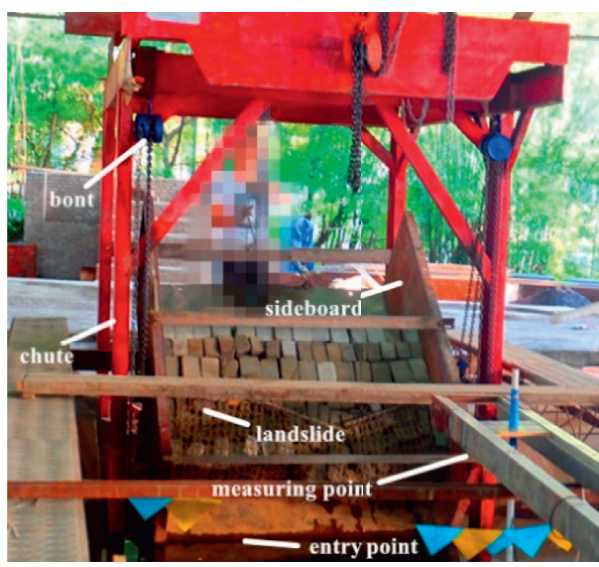

FIgURE 2: Chute.

2.3. Ship. We investigated the actual situations regarding waterway transportation in the Three Gorges Reservoir Area from 2016 to 2017. The volume of water freight was 166 billion tons in 2017, which was $10.7 \%$ higher than that in 2016. The volume of the water freight accounted for $15.4 \%$ of the total combined freight volume, which increased by $0.9 \%$ from 2016. In 2017, there were 187.61 billion tons of cargo turnover, an increase of $10.4 \%$ relative to 2016 . The cargo turnover by water accounted for $63.3 \%$ of the total transportation cargo turnover, an increase of $0.5 \%$ compared to 2016. The average waterway freight transportation distance was $1127 \mathrm{~km}$, and the main form of cargo transportation was container ships. Owing to the constraints of the river depth and flow conditions, this study selected a $3500 \mathrm{t}$ container ship as the research object. The ship model is shown in Figure 3.

The ship model had the same scale ratio $(1: 70)$ as the river model. During the model test, the ship remained in a fully loaded state. The ship parameters are shown in Table 1.

2.4. Mooring System. A ship's mooring system refers to the mooring cables and mooring machinery used when the ship is moored near a dock, shore, buoy, or other facilities. The main functions of the mooring system are to limit the motion of the berthing ship and to ensure the safety of the normal operation of the ship. A tensioned mooring system generally comprises a polyester cable, which can effectively 


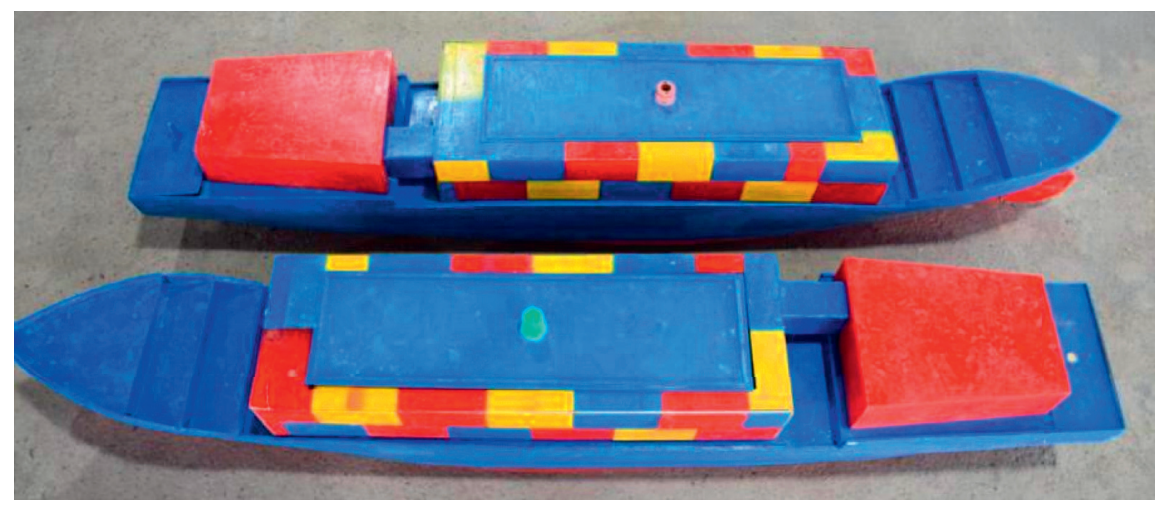

FIGURE 3: Ship model.

TABLE 1: Ship type parameters.

\begin{tabular}{lcc}
\hline Ship type parameter & Real ship & Ship model \\
\hline Length of ship (m) & 94.5 & 1.350 \\
Type width (m) & 15.1 & 0.216 \\
Depth (m) & 9.0 & 0.129 \\
Design draught (m) & 5.6 & 0.080 \\
Block coefficient & 0.7 & 0.7 \\
Full load displacement (t/g) & 3500 & 10,150 \\
\hline
\end{tabular}

increase the carrying capacity of the mooring cable. The mooring radius of a tensioned mooring system is small. In addition, it can be installed easily and at a low cost.

In this study, based on the characteristics of ship navigation in the Three Gorges Reservoir, combined with the instantaneity and particularity of landslide-induced waves, a mooring system was developed for ships rapidly anchored in landslide-induced waves. The mooring lines were made by the metal chains and leaf spring to ensure weight similarity and elastic similarity. The constitutive relations of the mooring lines are shown in Figure 4.

The parameters of the mooring line are listed in Table 2.

The advantages and disadvantages of bow and stern anchoring and multipoint anchoring were analysed in relation to landslide-induced waves. The multipoint mooring system adopted the form of four anchor chains, and the anchor chains were fixed at the port and starboard sides of both the stern and stem. The form of the anchor at the bow and stern resulted from throwing in the centre line of the ship's stem and stern separately. The coordinates of anchor points are shown in Table 3, the vertical coordinates of all anchor points are $-0.74 \mathrm{~m}$, and the origin of the reference system is located at the undisturbed free surface at point " $\mathrm{A}$ " of Figure 5.

The two mooring chain forms are shown in Figure 5.

2.5. Operating Model. According to a preliminary investigation conducted by a research group [17], landslides can easily occur from $20^{\circ}$ to $60^{\circ}$ on the bank slope of the Wanzhou section of the Three Gorges Reservoir. Through a mathematical statistical analysis [18], it was determined that when a landslide occurs, the average dip angle is $36^{\circ}$. Combined with the experimental conditions and theoretical

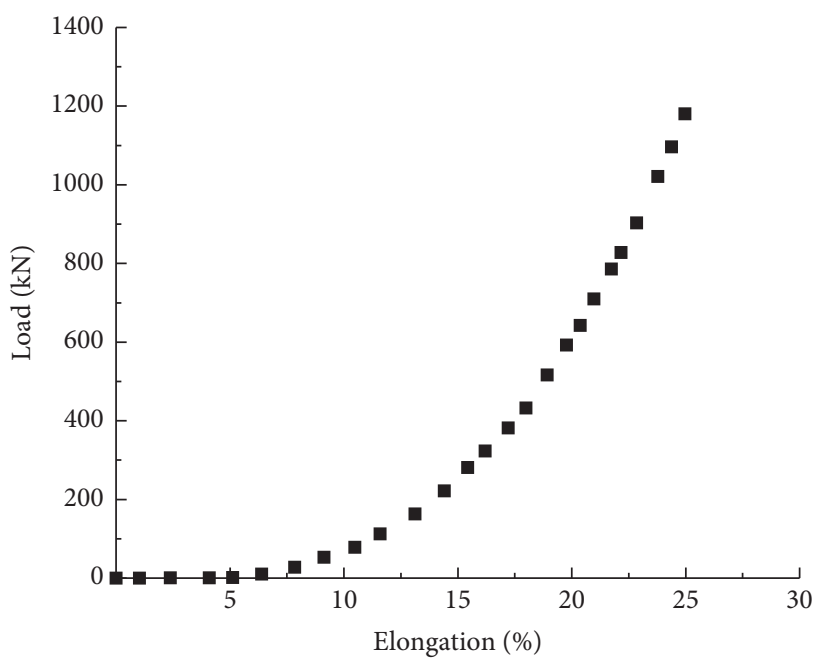

FIgURE 4: Constitutive relations of the mooring lines.

TAble 2: Parameters of mooring line.

\begin{tabular}{lccc}
\hline Type $(\mathrm{mm})$ & Diameter $(\mathrm{mm})$ & Length $(\mathrm{mm})$ & Width $(\mathrm{mm})$ \\
\hline 1.2 & 1.2 & 1.2 & 0.6 \\
\hline
\end{tabular}

TABLe 3: Position of anchor.

\begin{tabular}{lccc}
\hline Number & Coordinate & Number & Coordinate \\
\hline 1 & $(2.0,3.5)$ & 7 & $(-1.6,2.6)$ \\
2 & $(-2.0,3)$. & 8 & $(1.6,2.6)$ \\
3 & $(-7.6,1.7)$ & 9 & $(-7.4,2.4)$ \\
4 & $(-9.0,5.3)$ & 10 & $(8.0,5.3$ \\
5 & $(1.6,4.4)$ & 11 & $(-9.8,4.6)$ \\
6 & $(-1.6,4.4)$ & 12 & $(-8.6,1.7)$ \\
\hline
\end{tabular}

analysis results [18], in this study, when the dip angle was $40^{\circ}$, the high-energy invert efficiency between the landslide body and water body and maximum water level value of the landslide-induced wave changed. The impacts of the landslide-induced waves on the hydraulic structure were greater. The dip angle of the test was $40^{\circ}$, the test water depth was $0.74 \mathrm{~m}$, the length and width of the landslide volume were $1 \mathrm{~m}$, and the height was $0.4 \mathrm{~m}$. The typical working conditions are listed in Table 4. 


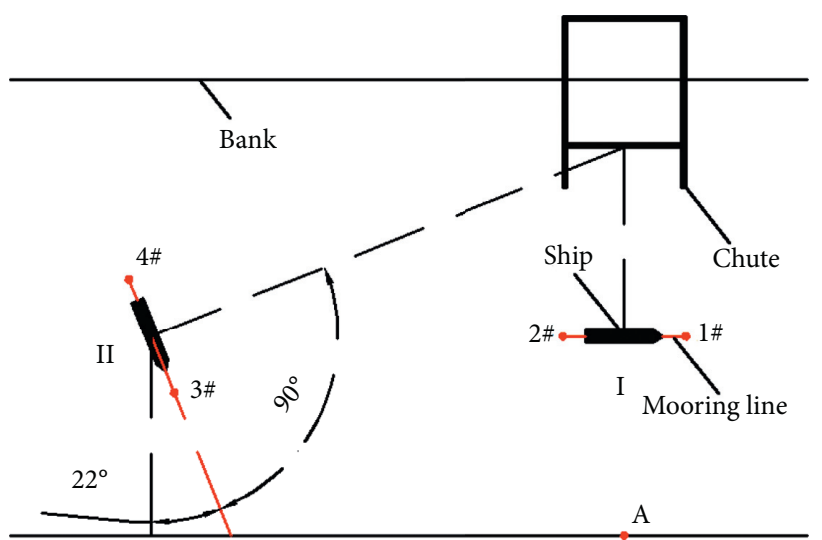

(a)

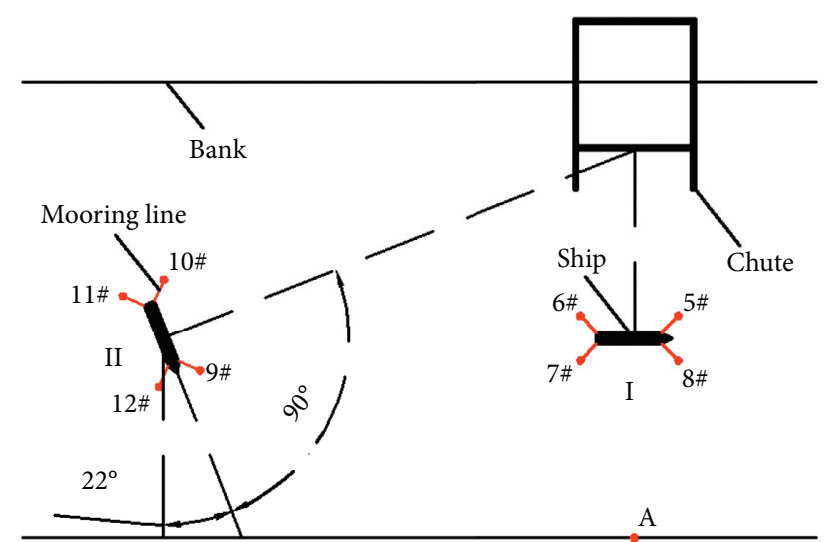

(b)

Figure 5: Mooring diagram of bow and stern and multipoint mooring. (a) Mooring at bow and stern. (b) Multipoint mooring.

TABLE 4: Working conditions.

\begin{tabular}{ccccc}
\hline No & Direction & Amount of cable chain & Location & $\begin{array}{c}\text { Measuring } \\
\text { point }\end{array}$ \\
\hline 1 & Beam sea & 4 & $\# 1$ & I \\
2 & Beam sea & 2 & $\# 2$ & II \\
3 & Beam sea & 2 & $\# 1$ & I \\
4 & Beam sea & 4 & $\# 2$ & II \\
5 & Head sea & - & - & I \\
6 & Beam sea & - & - & I \\
7 & Head sea & - & - & II \\
8 & Beam sea & - & - & II \\
\hline
\end{tabular}

2.6. Measuring Equipment. The UBL-2 ultrasonic measurement system operates in a master-slave mode. The measuring accuracy can reach $0.1 \mathrm{~mm}$, and the measurement range is $500 \mathrm{~mm}$. The ultrasonic transceiver sensor is placed at a certain depth under water, and the ultrasonic wave is transmitted straight up. The ultrasonic wave is reflected at the position of the water surface, and the reflected ultrasonic wave is received by the ultrasonic probe. The water level can be measured in real time by data analysis. During the model test, the ultrasonic measuring system was placed $30 \mathrm{~cm}$ below the water surface, and the measuring instrument was calibrated. The UBL-2 ultrasonic measurement system is shown in Figure 6(a).

The ship motion posture acquisition and analysis device was designed independently from the model test. It can capture the six degrees of freedom of ship in real time. The device adopted advanced Kalman filter technology to establish the mathematical model and error model for the degree-of-freedom measurement sensor. According to the system structure and measurement principle, the signal transmission and collection were completed, and then the preprocessed signal was transmitted to a host computer through serial communication. Then, the results were displayed on a designed user display interface. Before the model test, the system was calibrated, and the actual displacement was ultimately calculated according to the measurement principle and test data of the system.
The tension at the top of each mooring line was measured by the dynamic signal test and analysis system. It works as follows: it needs to arrange tension sensor at the top of the mooring lines; when landslide-induced wave causes the external changes, the amplitude of action potential of the measurement system changes accordingly; the tension sensor is a device that converts the physical signal into a measurable electrical signal. The tension at the top of the mooring line is analysed by conversion with the calibration data before the test. The measurement equipment is shown in Figure 6(b).

\section{Characteristics of Landslide-Induced Wave}

During the trial, moored ships were placed at points I and II, with different forms of cable-laying, in straight river channels. The mooring position of the ship was chosen as $0.5 \mathrm{~m}$ from the centre line of the river channel, inclined to the convex bank. The horizontal distance between position II and the water entry point of the landslide was $8.31 \mathrm{~m}$. During the trial, it was necessary to measure the wave height, period, and other parameters of each working condition. The measuring instruments were located $0.5 \mathrm{~m}$ away from the mooring position. In this position, the landslide-induced wave parameters could be measured accurately, and the influence of ships on such parameters could be reduced. Positions I and II were the monitoring points.

During the trial, a UBL-2 ultrasonic wave acquisition and analysis system was used to collect the data. By changing the water level above the probe and comparing it with the initial position data, it was possible to collect and calculate the real-time data of the landslide-induced waves at the point. The data acquisition interval was set at $0.0069 \mathrm{~s}$. During each test, the data collection was $50 \mathrm{~s}$ long. A total of 7250 free-surface elevation values were collected under each working condition. When the data acquisition was completed, based on the preset procedures, the wave number, maximum wave height, maximum period, significant wave height, and mean zero-crossing period were automatically calculated. The statistics regarding the wave elements at positions I and II are shown in Table 5. 


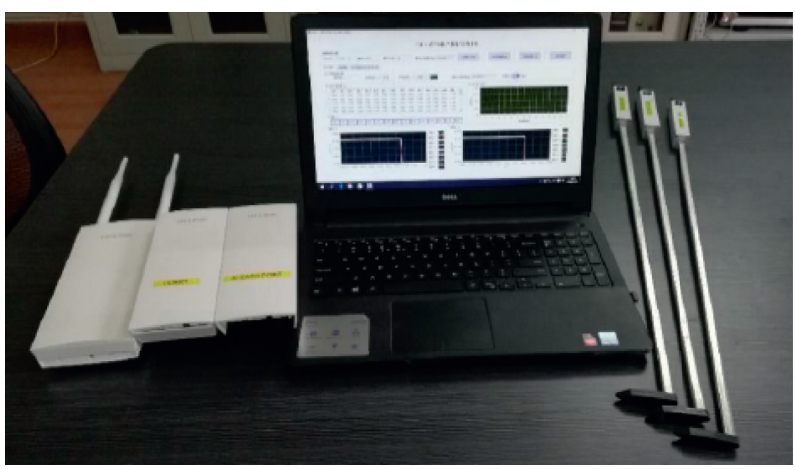

(a)

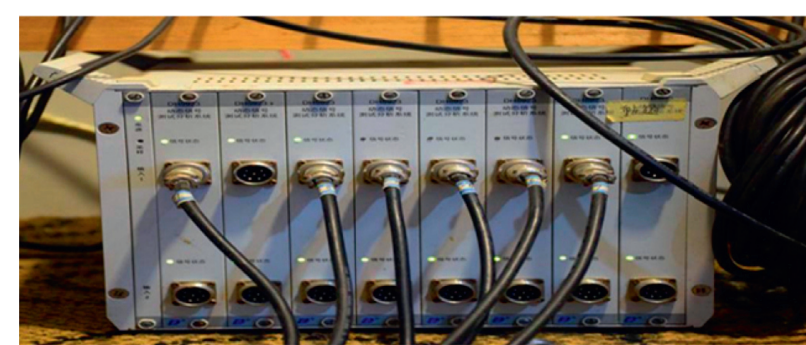

(b)

FIgURE 6: Measuring equipment. (a) UBL-2 ultrasonic measurement equipment. (b) Dynamic signal acquisition system.

TABLE 5: Statistics regarding wave elements at positions I and II.

\begin{tabular}{lcc}
\hline Factor & Position I & Position II \\
\hline Total number & 24 & 27 \\
Maximum wave height $(\mathrm{cm})$ & 4.149 & 1.498 \\
Maximum period $(\mathrm{s})$ & 2.662 & 0.779 \\
$1 / 10$ wave height $(\mathrm{cm})$ & 3.356 & 1.354 \\
$1 / 10$ period $(\mathrm{s})$ & 1.969 & 1.01 \\
$1 / 3$ wave height $(\mathrm{cm})$ & 2.135 & 1.089 \\
$1 / 3$ period $(\mathrm{s})$ & 2.465 & 1.839 \\
Average wave height $(\mathrm{cm})$ & 1.126 & 0.714 \\
Average period $(\mathrm{s})$ & 1.672 & 1.392 \\
\hline
\end{tabular}

As can be seen from Table 5, there was a slight difference between the total number of waves at positions I and II, even under the same landslide and channel conditions. The main cause of this was the distance between positions I and II and the water entry point of the landslide. The landslide-induced waves were superimposed on each other in the course of propagation away from the entry point, leading to slight differences between the total wave numbers at the monitoring position and the wave numbers at each position during propagation. The time series of the free-surface elevation of a landslide-induced wave at position I is shown in Figure 7.

It can be seen from Figure 7 that the landslide body slid into the channel and exchanged energy with the water body, causing fluctuations in the water level. The maximum water level of the monitoring appeared in a short time, and the peak was steep. As time elapsed, the minimum value appeared, but the maximum and minimum value were asymmetrical. It was observed in the tank, as the landslideinduced wave propagated along the river, the wave amplitude decreased gradually.

\section{Hydrodynamic Performance of Moored Ship}

When navigating ships suddenly encounter landslide-induced waves, active mooring systems should be adopted to avoid risk. When a ship is under a mooring condition, the roll characteristics of the moored ship can be studied to determine whether the ship will roll over. Whether the mooring cable will break can be analysed by exploring the

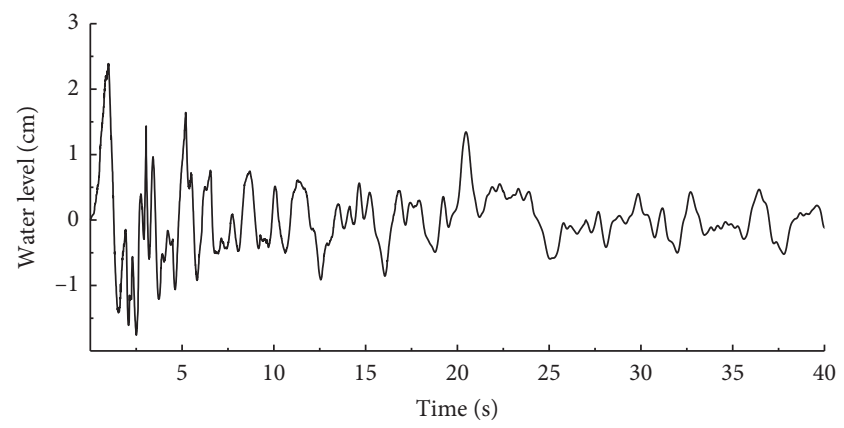

Figure 7: Water level of landslide-induced wave at position I.

changes in the top tension in the mooring cables. Therefore, this section mainly addresses the ship's roll and pitch and the tension variations in the mooring cables. A motion sensor for the ship movement is placed at a premarked position at the ship's centre of gravity. The $X$ direction is along the captain's direction, and the ship's stem in the stern direction is positive. The $Y$ direction is along the ship's width direction, and the starboard to port side is positive. The motion sensor for ship movement collects data every $0.25 \mathrm{~s}$, with a duration of $50 \mathrm{~s}$. For each test condition, 200 data values are collected.

4.1. Rolling Characteristics of Ship at Bow and Stern Mooring. As can be seen from Figure 8, when the landslide-induced wave interacts with the ship, the rolling time series changes periodically under the actions of the mooring cables at the bow and stern. Under this working condition, the maximum rolling angle of the ship is $9.39^{\circ}$ and does not reach the motion amplitude threshold in severe sea conditions; thus, the mooring ship is in a safe state. In the process of the landslide-induced wave propagation, the energy gradually attenuates, and the ship relies on its own restoring force and the tension at the top of the mooring cable; therefore, the rolling motion amplitude of the ship gradually decreases and finally becomes stable.

As shown in Figure 9, the rolling motion amplitude of the ship at position II changes quickly under the interactions between the landslide-induced wave and ship. As position II 


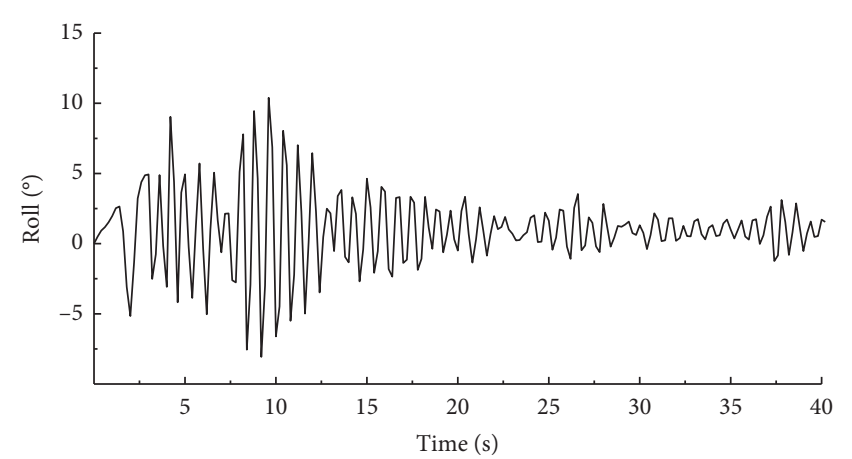

FIGURE 8: Time series of ship roll motion when moored at position I with bow and stern mooring.

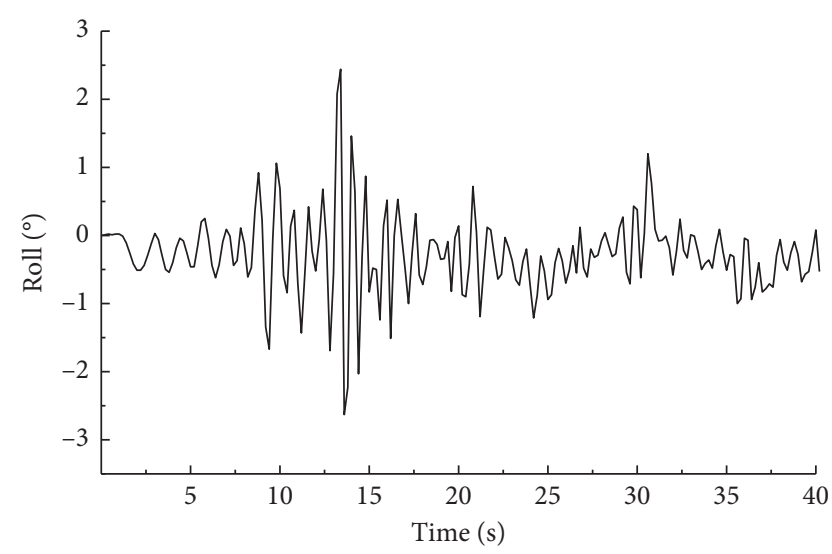

Figure 9: Time series of ship roll motion when moored at position II with bow and stern mooring.

is far away from the point where the landslide enters the water, the landslide-induced wave loses energy in its propagation to position II. The maximum rolling angle is $2.69^{\circ}$. With a further decrease in the landslide-induced wave energy, the rolling motion amplitude of the ship also gradually decreases, and the rolling motion of the ship changes periodically. The entire process changes gently, so there is little risk of the ship capsizing.

\subsection{Tension Characteristics of Mooring Cable under Mooring} Conditions at Bow and Stern. As can be seen from Figure 10, the ship oscillates slightly at position I inside the river course, based on the moorings at the bow and stern. The change trends of the tension at the top of the mooring cables are basically identical. The maximum tension at the stern of the mooring cables is larger than that at the stem. It can be seen that the durations of the tension variations of the mooring cables at the top of the stems are longer and can play a more important role.

\subsection{Characteristics Comparison of Ship Motion Response.} The motion response amplitude and changes in the top tensions of the mooring cables at different positions in the river course are compared and analysed. At position I, because the mooring position is close to the point where the landslide body enters the water, the ship is greatly impacted by the landslide-induced waves. When the ship is moored at position II, the effect of the landslide-induced waves is small. Based on the model test and theoretical analysis, this study analyses the rolling characteristics of the ship mooring and tension characteristics of the mooring cables at the bow and stern in landslide-induced wave waters, aiming to improve the safety of ship navigation.

As shown in Figure 11, if the ship is moored in typical locations within the river course, the degrees of change in the amplitude of the rolling motion and those of the longitudinal motion in the landslide-induced wave are different. When the ship is sailing and receives a warning of landslide-induced waves, it should reduce its sailing speed, anchor fast, and moor in the river course. Based on the research results, ships should anchor at the bow and stern or moor at multiple points, to reduce the amplitude of the rolling motion as much as possible. We can get the data of ship motions by the posture acquisition and analysis device. When a ship is moored in the landslide-induced wave section, the mooring at the bow and stern can better limit the amplitudes of the rolling and longitudinal motions of ships. It has the additional advantage of enabling fast ship anchoring. Conversely, the symmetrical throwing of double anchors can improve the working efficiency.

As can be seen from Figure 11, when the ship is moored at the far end of a straight channel (that is, position II in the test) and when the ship adopts mooring at the bow and stern and multipoint mooring, the amplitudes of the rolling and pitching motions all meet the requirements of the "Technical Rules for Statutory Inspection of Inland River Vessels" at position II of the river course. Moreover, the energy of the landslide-induced wave is smaller than that at position I. From Figure 8, it can be concluded that when the ship uses multipoint mooring anchors at position II of the river course, the maximum roll angle is $4.03^{\circ}$, and the maximum pitch angle is $4.09^{\circ}$. The same figure shows that bow and stern mooring is better than multipoint mooring. Through comparison and analysis, it can be seen that a ship can easily adopt mooring at the bow and stern. This can improve the stability of the mooring ship; additionally, when the risk of a landslide-induced wave is reduced, the ship can anchor fast and/or leave the landslide-induced wave waters as soon as possible, so as to prevent the occurrence of secondary injury accidents.

4.4. Dynamic Characteristics of Mooring System. In this section, the variations in the maximum tension at the mooring cables are considered under the same landslide volume and slope angle, but different mooring conditions. As can be seen from Figure 12, when the ship is moored in position $\mathrm{I}$, the maximum top tension of the mooring cables is larger for the bow and stern mooring than for the multipoint mooring. Under the mooring at the bow and stern, the maximum tension at the top of the mooring cable in the bow is $38.75 \mathrm{~N}$, and the maximum tension at the stern is $61.64 \mathrm{~N}$. The maximum tensions at the multipoint mooring lines \#1, 


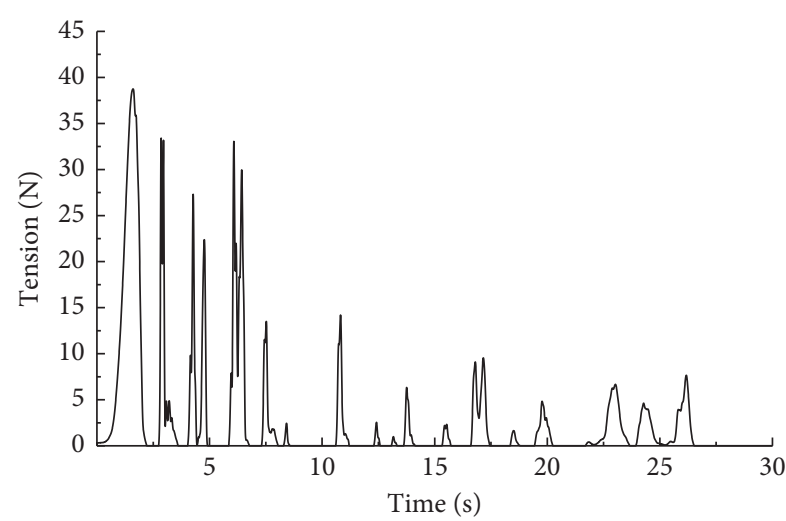

(a)

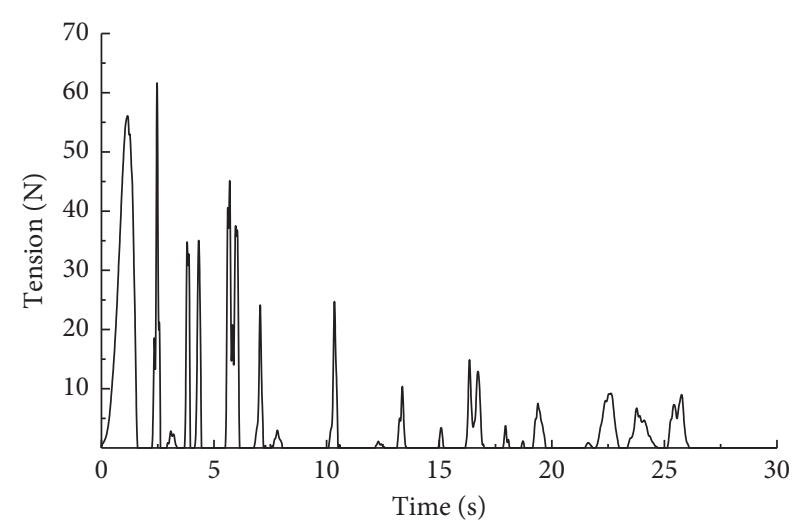

(b)

FIGURE 10: Time series of the tension at the bow and stern mooring lines when the ship is moored at position I with bow and stern moorings. (a) Time series of tension at bow mooring line. (b) Time series of tension at the stern mooring line.

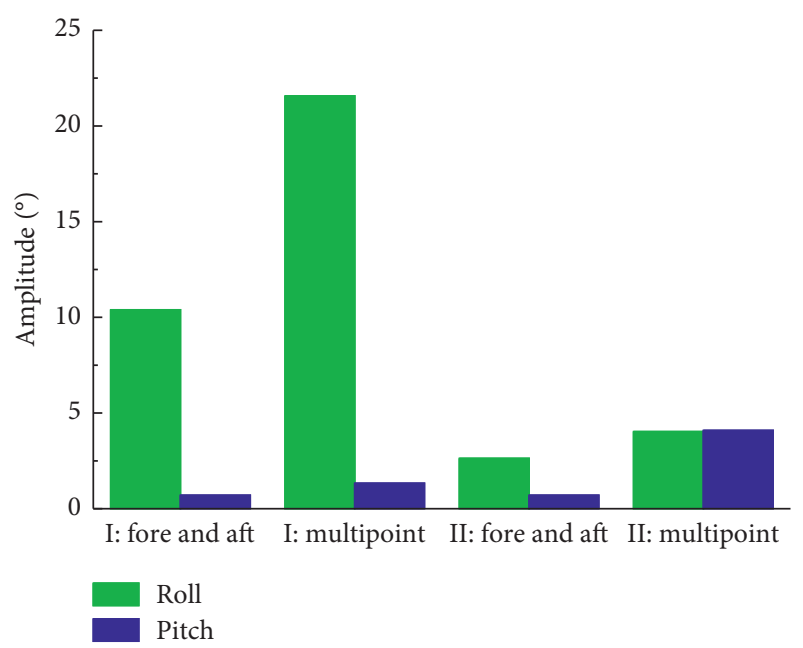

Figure 11: Comparative study of ship motion response characteristics under different operating conditions.

$\# 2$, \#3, and \#4 are $38.36 \mathrm{~N}, 31.48 \mathrm{~N}, 28.66 \mathrm{~N}$, and $31.2 \mathrm{~N}$, respectively. If multipoint mooring is adopted, the tension in each mooring line is relatively uniform. However, owing to the large number of mooring lines, the ship may need to anchor several times, making it difficult to cope with landslide-induced waves. Combined with the changes in the amplitude of roll and pitch motions under the working conditions, it is easier to adopt bow and stern mooring. However, the number of mooring lines is small and the maximum tension at each mooring line is large; thus, they may break.

As can be seen from Figure 12, when a ship is moored with bow and stern mooring, if the length of the mooring cable, weight in the water per unit length, diameter of the mooring cable, and other physical quantities are the same, the maximum tension in the bow line significantly differs from that of the stern line. When the ship is moored at position $\mathrm{I}$, the maximum tension at the bow mooring line is $38.75 \mathrm{~N}$, and the maximum tension at the stern mooring line is $61.64 \mathrm{~N}$. When the ship is moored at position II, the maximum tension at the bow mooring line is $10.96 \mathrm{~N}$, and

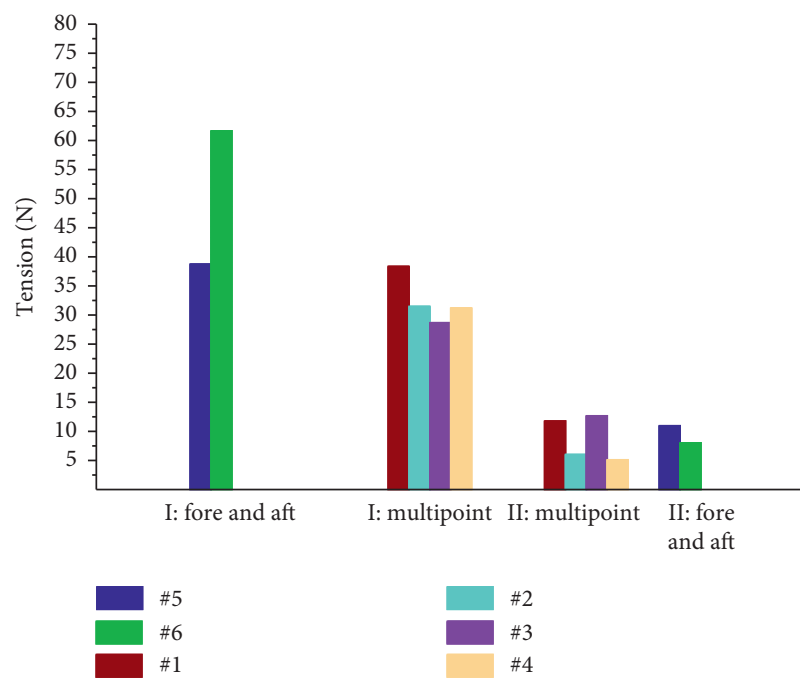

FIgURE 12: Comparative study on tension characteristics of mooring cables under different working conditions.

the maximum tension at the stern mooring line is $8.03 \mathrm{~N}$. The maximum tensions of the mooring cables at position II are small, with high security. The main reason for this is that the landslide-induced waves spread in the river channel. After propagating to position II, the energy of the landslideinduced wave is small, the effect on the ship from the landslide-induced wave is small, and the amplitude of motion for the ship's respective degrees is small; this leads to the top tension of the mooring cable being small.

As can be seen from Figure 12, when the ship is moored at position I with bow and stern mooring, if the physical quantities of the mooring cables are the same, the maximum tension of the bow line will significantly differ from that of the stern line. The main reason is that the landslide-induced waves are centred on the point where the landslide body enters the water and spreads by scattering; thus, the ship's stem and stern are subjected to different external forces, leading to the difference in the maximum tensions at the mooring lines. As shown in Figure 10, the top tension of the 
stern line is larger than that of the bow line. In general, adequate attention to these aspects should be paid when moored ships are subjected to landslide-induced waves.

\section{Study on Movement of Ship Emergency Handling}

When a ship is sailing in the Three Gorges Reservoir, it navigates through a channel on the starboard side of the ship. During the trial, landslide-induced waves have a strong impact and are instantaneous. To prevent the ship from colliding with the river bank under the action of a landslideinduced wave (which would affect the accuracy of the measurement results), the route of ship is determined to be $0.5 \mathrm{~m}$ from the centre line of the channel to the right bank, and the distance from the shore is $3.5 \mathrm{~m}$. At position I, the ship is moored at the intersection of the centre line of the landslide water point and the route, and the distance from the opposite bank is $3.5 \mathrm{~m}$. Position II is located on the ideal route, and the horizontal distance from monitoring point $\mathrm{I}$ is $8.3 \mathrm{~m}$. The details are shown in Figure 13 .

\subsection{Influence of Wave Direction on Ship Rolling Motion.} When a ship is moored at position I, the landslide body enters the water, forms a landslide-induced wave, and the ship adjusts its sailing direction to ensure that the ship is in a safe state. In the model test, the gravity centre of the ship must be maintained at the same level, and the amplitude of the rolling and pitching motions must be analysed for the cases of head seas and beam seas.

As can be seen from Figure 14, when the ship encounters a transverse wave, the roll angle changes significantly, and the maximum roll angle is $8.2^{\circ}$. As time elapses, the energy of the landslide-induced wave gradually decreases, and the roll angle gradually decreases. When the ship encounters a head wave, the maximum roll angle is $2.51^{\circ}$. The amplitude of the rolling motion is close to gentle after $25 \mathrm{~s}$ of the landslide-induced wave, and the average amplitude of the rolling motion in the transverse wave is $0.62^{\circ}$. The research shows that when a ship encounters landslide-induced waves during navigation, the sailing direction should be adjusted to reduce the impacts of landslide-induced waves on the side of the ship; thus, the amplitude of the rolling motion can be reduced.

5.2. Influence of Position on Rolling Motion. The distance from the water entry point of the landslide to position I is different from that to position II, and the effect of the landslide-induced waves on the ship is different. The ship in position I is subjected to the direct action of a landslideinduced wave, which produces a large amplitude of the roll motion; the maximum roll angle is $8.2^{\circ}$. As time elapses, the amplitude of the roll motion gradually decreases. A ship in position II is subjected to the action of the landslide-induced waves, and the amplitude of the rolling motion changes slightly at first. When the ship's rolling period is close to the wave period at positions I and II, the ship resonates. The amplitude of the rolling motion increases, and the maximum roll angle is $2.86^{\circ}$. As time elapses, the energy of the

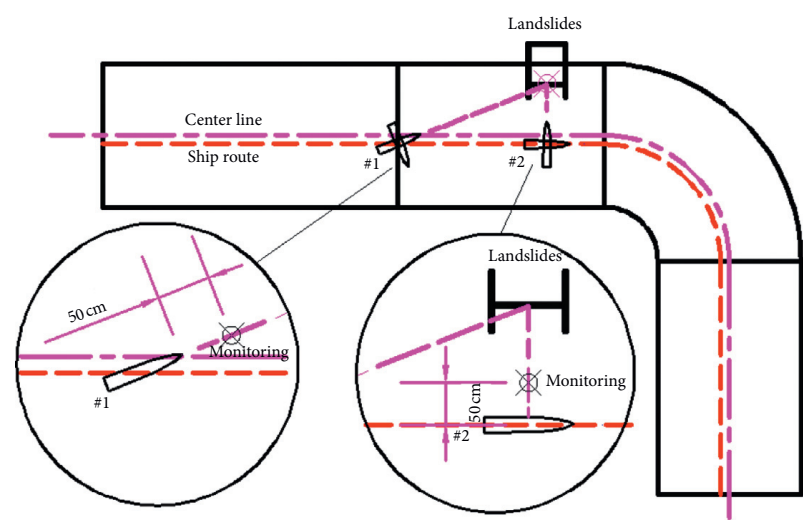

FIGURE 13: Schematic diagram of ship precontrol research scheme.

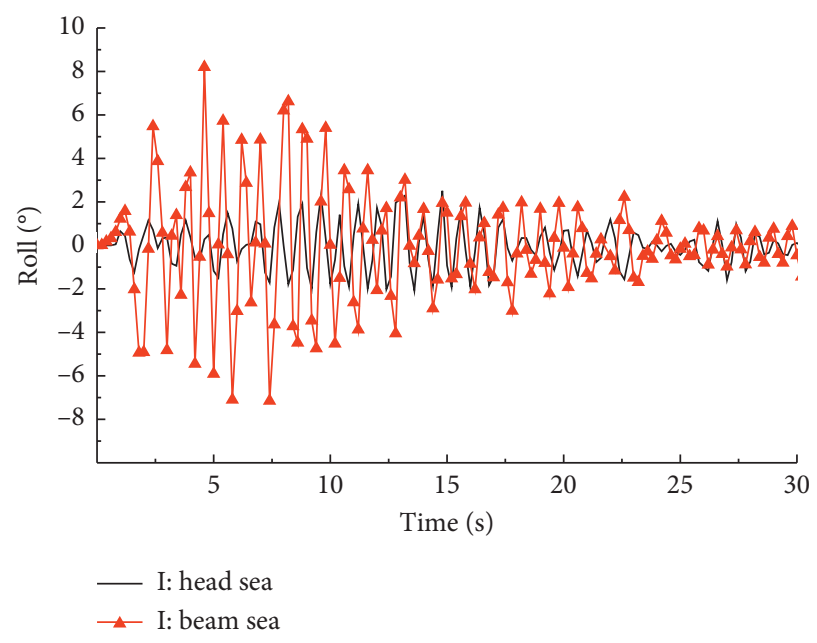

FIgURE 14: Time series of ship roll motion under different wave directions without mooring system.

landslide-induced wave gradually decreases, and the same happens to the amplitude of the rolling motion, which is in a relatively stable state. As can be seen from the curve comparison in Figure 15, the farther the ship is from the water entry point of the landslide-induced wave, the less affected it will be by landslide-induced waves. Therefore, in an actual navigation process, an early warning system for landslide-induced waves should be used to reasonably determine the location of the water entry point of landslideinduced waves in advance, so as to increase the distance from the navigating ship to the water entry point, as well as to allow for the attenuation of landslide-induced waves, so that the risks in the navigation process can be avoided.

5.3. Comparison. This section mainly compares and analyses the characteristics of the rolling and longitudinal motions of a ship under different working conditions. When the ship sails to position I, the landslide-induced wave acts on the side of the ship, and the amplitude of the roll motion is evidently larger than that of the longitudinal motion. The ship should adopt anti-rolling measures to improve 


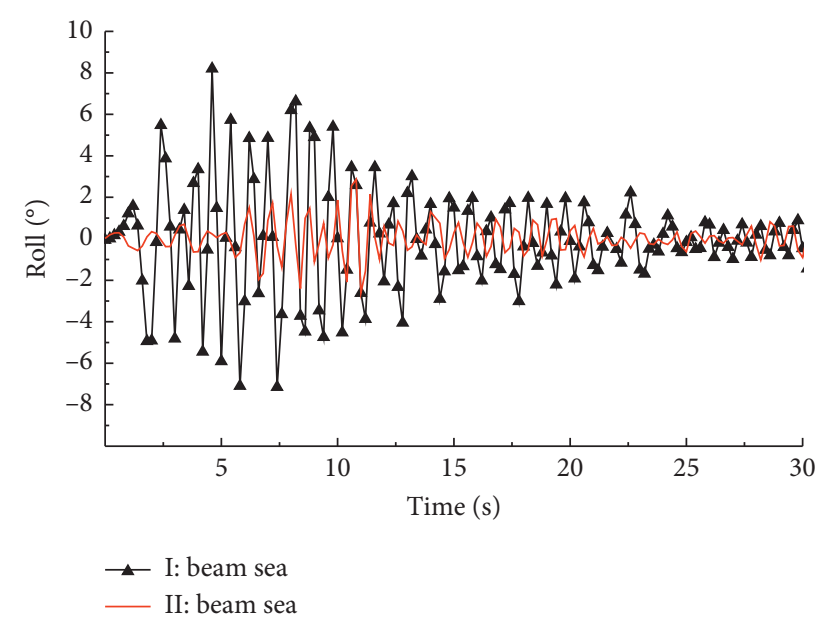

FIgURE 15: Time series of ship roll motion at different navigational positions without mooring system.

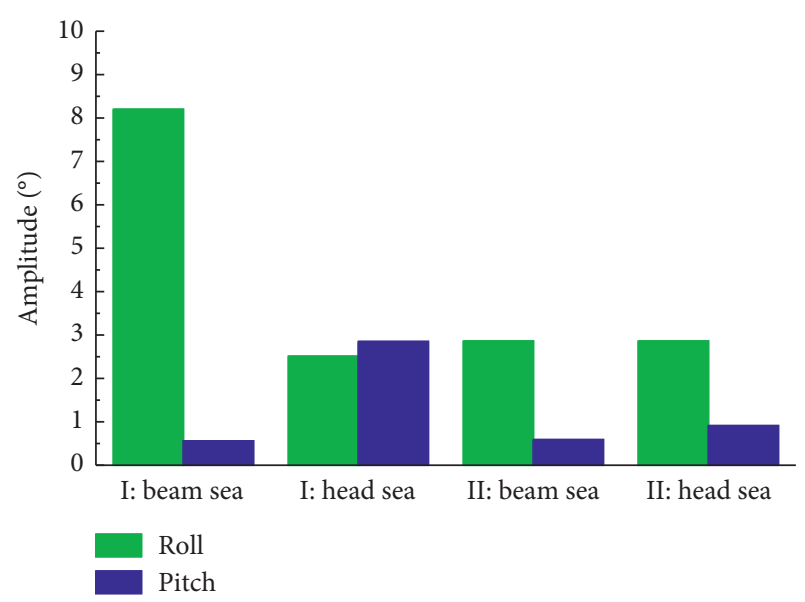

FIGURE 16: Comparative analysis diagram of ship motion amplitude under various working conditions.

navigation safety, such as adopting a catamaran, setting up anti-rolling water tanks, and installing anti-rolling fins. When the ship is close to the water entry point of the landslide, it should change its direction quickly, so as to address the occurrence of landslide-induced waves (when facing such waves). In this way, the amplitude of the roll motion of the ship can be greatly reduced, and the amplitude of the pitch motion of the ship can be appropriately increased so that the ship is in a relatively safe state.

The energy of a landslide-induced wave decreases with an increase in the propagation distance. To reduce the direct effects of landslide-induced waves, a ship should move away from the area as soon as possible to increase the distance between the ship and water entry point of the landslide, so as to reduce the direct effect of landslide-induced wave and to ensure navigation safety. (Figure 16)

\section{Conclusion}

Based on a physical model test with a large-scale ratio, this study investigates the propagation characteristics of landslide-induced waves in the Wanzhou section of the Three Gorges Reservoir Area and analyses the influences of the navigation position and direction of the landslide-induced waves on the motion characteristics. By prejudging the relative positions of the water entry point of the landslide and ship, precontrol methods (e.g. anchoring fast or steering) can be employed. The main conclusions of this study are as follows:

(1) The landslide-induced wave shows an evident nonlinearity, with a steep peak and flat trough. During the landslide-induced wave propagation, the waves are superimposed on each other, resulting in different total wave numbers at different monitoring points in the river course.

(2) When mooring at the bow and stern, the maximum tension on the stern mooring line is larger than that at the bow line. The change in tension on the bow mooring line lasts for a long time. The tension on the stern mooring line is larger than that on the bow line. Accordingly, adequate attention should be paid when mooring ships subjected to landslide-induced waves.

(3) The speed of the ship should be reduced rapidly during the course of the ship's sailing. The ship should be fixed in the river course by means of mooring at the bow and stern. Thus, it can improve the stability of moored ships; in addition, when the risk of the landslide-induced wave is reduced, the anchor can be quickly collected, and the ship can leave as soon as possible to prevent the occurrence of secondary injury accidents.

(4) When the ship sails to position I, the landslide-induced wave acts on the side parts of the ship, and the amplitude of the rolling motion is evidently larger than that of the longitudinal motion. When the ship is close to the water entry point of a landslide, it should change its direction quickly, so as to manage the occurrence of landslide-induced waves when facing such waves. Accordingly, the amplitude of the roll motion of the ship can be greatly reduced, and the amplitude of the pitch motion of the ship can be appropriately increased.

\section{Data Availability}

The data used to support the findings of this study are available from the corresponding author upon request.

\section{Conflicts of Interest}

The authors declare that there are no conflicts of interest regarding the publication of this paper.

\section{Acknowledgments}

This study was financially supported by the National Natural Science Foundation of China (51479015), the Social Science and Technology Innovation Program for People's Livelihood 
in Chongqing (cstc2019ngzx0017, cstc2020jscx-lyjsAX0009, and cstc2019jscx-lyjsAX0008), and the Science and Technology Program of the Chongqing Education Commission (KJQN201900735).

\section{References}

[1] Q. Huang and X. Huang, Warning and Forecast Manual of Landslide Disaster in the Three Gorges Reservoir Area, Geological Publishing House, Beijing, China, 2014.

[2] V. Heller, "Scale effects in physical hydraulic engineering models," Journal of Hydraulic Research, vol. 49, no. 3, pp. 293-306, 2011.

[3] V. Heller, "Self-similarity and Reynolds number invariance in Froude modelling," Journal of Hydraulic Research, vol. 55, no. 3, pp. 293-309, 2017.

[4] V. Heller and W. H. Hager, "Impulse product parameter in landslide generated impulse waves," Journal of Waterway, Port, Coastal, and Ocean Engineering, vol. 136, no. 3, pp. 145-155, 2010.

[5] B. Huang, S. C. Wang, and Y. B. Zhao, "Impulse waves in reservoirs generated by landslides into shallow water," Coastal Engineering, vol. 123, pp. 52-61, 2017.

[6] V. Heller and W. H. Hager, "Wave types of landslide generated impulse waves," Ocean Engineering, vol. 38, no. 4, pp. 630-640, 2011.

[7] H. Ersoy, M. Karahan, K. Gelişli et al., "Modelling of the landslide-induced impulse waves in the Artvin Dam reservoir by empirical approach and 3D numerical simulation," Engineering Geology, vol. 249, pp. 112-128, 2019.

[8] G. Ruffini, V. Heller, and R. Briganti, "Numerical modelling of landslide-tsunami propagation in a wide range of idealized water body geometries," Coastal Engineering, vol. 153, Article ID 10358, 2019.

[9] H. Fuchs, V. Heller, and W. H. Hager, "Impulse wave runover: experimental benchmark study for numerical modelling," Experiments in Fluids, vol. 49, no. 5, pp. 985-1004, 2010.

[10] G. S. Miller, W. Andy Take, R. P. Mulligan et al., "Tsunamis generated by long and thin granular landslides in a large flume," Journal of Geophysical Research-Oceans, vol. 122, no. 1, pp. 653-668, 2017.

[11] B. L. Huang, Y. P. Yin, X. T. Chen et al., "Experimental modeling of tsunamis generated by subaerial landslides: two case studies of the three gorges reservoir, China," Environmental Earth Sciences, vol. 71, no. 9, pp. 3813-3825, 2014.

[12] G. B. Kim, W. Cheng, R. C. Sunny et al., "Three dimensional landslide generated tsunamis: numerical and physical model comparisons," Landslides, vol. 17, no. 5, pp. 1145-1161, 2020.

[13] B. C. McFall and H. M. Fritz, "Physical modelling of tsunamis generated by three-dimensional deformable granular landslides on planar and conical island slopes," Proceedings of the Royal Society, A-Mathematical Physical and Engineering Sciences, vol. 472, no. 2188, Article ID 20160052, 2016.

[14] B. C. McFall, F. Mohammed, H. M. Fritz et al., "Laboratory experiments on three-dimensional deformable granular landslides on planar and conical slopes," Landslides, vol. 15, no. 9, pp. 1713-1730, 2018.

[15] F. Mohammed and H. M. Fritz, "Physical modeling of tsunamis generated by three-dimensional deformable granular landslides," Journal of Geophysical Research-Oceans, vol. 118, no. 6, p. 3221, 2013.

[16] V. Heller, M. Moalemi, R. D. Kinnear et al., "Geometrical effects on landslide-generated tsunamis," Journal of Waterway
Port Coastal and Ocean Engineering, vol. 138, no. 4, pp. 286-298, 2012.

[17] P. Y. Yuan, P. Y. Wang, and Yu Zhao, "Physical modelling of roll and pitch motions of travelling or stationary ship in largescale landslide-generated waves," Advances in Civil Engineering, vol. 2020, Article ID 8857604, 11 pages, 2020.

[18] P. Y. Yuan, P. Y. Wang, and Yu Zhao, "Study on the Steepness of Landslide-Induced Wave and Nonlinear Motion of Container Ships," Applied Sciences-Basel, vol. 10, no. 6, 2020. 